Int. J. Dev. Biol. 63: 631-639 (2019)

https://doi.org/10.1387/ijdb.190113mp

\title{
Xenopus laevis FGF16 activates the expression of genes coding for the transcription factors Sp5 and Sp5I
}

\author{
MICHAEL ELSY, ABIGAIL ROWBOTHAM, HANNAH LORD, HARRY V. ISAACS and MARY E. POWNALL* \\ Biology Department, University of York, UK
}

\begin{abstract}
Fibroblast growth factors (FGFs) comprise a family of signalling molecules with essential roles in early embryonic development across animal species. The role of FGFs in mesoderm formation and patterning in Xenopus has been particularly well studied. However, little is known about FGF16 in Xenopus. Using in situ hybridisation, we uncover the expression pattern of FGF16 during early Xenopus laevis development, which has not been previously described. We show that the zygotic expression of FGF16 is activated in the mesoderm of the early gastrula as a ring around the blastopore, with its first accumulation at the dorsal side of the embryo. Later, FGF16 expression is found in the otic vesicle, the branchial arches and the anterior pituitary, as well as in the chordal neural hinge region of the tailbud. In addition, we show that FGF16 can activate the MAPK pathway and expression of sp5 and sp5I. Like FGF16, sp5 is expressed in the otic vesicle and the branchial arches, with all three of these genes being expressed in the tailbud. These data provide evidence that FGF16 is present in the early mesoderm and can activate the expression of developmentally important transcription factors.
\end{abstract}

KEY WORDS: mesoderm, secreted growth factor, cell signaling, transcriptional regulation

Fibroblast growth factors (FGFs) are small polypeptide signalling molecules defined by a conserved 120-140 amino acid core and their high affinity for heparan sulfate (Goetz \& Mohammadi, 2013). FGFs signal through a family of tyrosine kinase receptors (Zhang etal., 2006) coded for by four distinct FGF receptor (FGFR) genes that can be differentially spliced (Johnson et al., 1991). This, together with multiple distinct ligands, leads to the impressive complexity underlying FGF signalling. Activation of the FGF pathway involves the formation of a tripartite signalling complex of FGF ligand, heparan sulfate, and FGFR (Turnbull et al., 2001). Receptor dimerization activates one of four downstream signal transduction pathways: mitogen-activated protein kinase (MAPK), phospholipase-C $\gamma 1$ (PLC- $\gamma$ 1), phosphatidylinositol 3-kinase (PI-3 kinase) or Janus kinase/signal transducer and activator of transcription (Jak/STAT) (Dorey \& Amaya, 2010; Ornitz \& Itoh, 2015). The autophosphorylation of tyrosine residues within the FGFR intracellular domain results in the phosphorylation of $F R S 2 \alpha$, a kinase substrate constitutively associated with the FGFR, and the subsequent recruitment of the GRB2 adapter protein. GRB2 then recruits the guanine nucleotide exchange factor, son of sevenless (SOS) (Ong et al., 2000). For the activation of the MAPK pathway, SOS activates Ras GTPase, in turn activating Raf (a MAP kinase kinase kinase), Mek (a MAP kinase kinase) and MAPK
ERK in a cascade of phosphorylation events. Phosphorylated ERK translocates to the nucleus and modifies the activity of Ets family transcription factors, resulting in effects on gene expression downstream of FGF signalling (Randi et al., 2009).

There are 22 members of the FGF family, which are divided into subfamilies: paracrine FGFs (FGF1-10, 16-18, 20, 22), intracellular FGFs (FGF11-14), and endocrine FGFs (FGF15/19, 21,23). Most FGFs require N-terminal signal peptides for secretion (Käll et al., 2004). However, the FGF9 group, including FGF 9, 16 and 20, lack cleavable signal peptides (Itoh \& Ornitz, 2004). The secretion of these FGFs relies upon un-cleavable bipartite signals in the N-terminal and central hydrophobic region (Miyakawa et al., 1999; Revest et al., 2000), with secretion, nonetheless, requiring the Golgi and the endoplasmic reticulum (ER) (Miyakawa \& Imamura,2003).

FGF16 was originally identified in the rat heart (Miyake et al., 1998) and has known cardiogenic and cardioprotective roles (Hotta et al., 2008; Lu et al., 2008; Wang et al., 2015), as well as roles in the development of the chick inner ear (Chapman et al.,

Abbreviations used in this paper: FGF, fibroblast growth factor; MAPK: mitogen-activated protein kinase (also called ERK); Sp5 and Sp5l, proteins related to the human transcription factor Sp 1; X.laevis, Xenopus laevis; X.tropicalis, Xenopus tropicalis.

*Address correspondence to: Mary E. Pownall. Biology Department University of York, York, YO10 5DD United Kingdom. Tel +44 (0) 1904328692.
Fax +44 (0) 1904328505 . E-mail: betsy.pownall@york.ac.uk

Submitted: 19 June, 2019; Accepted: 11 September, 2019.

ISSN: Online 1696-3547, Print 0214-6282 
2006; Olaya-Sánchez et al., 2017), the formation of pectoral fin buds in zebrafish (Nomura et al., 2006), and the specification of GABAergic neurons and oligodendrocytes in the zebrafish forebrain (Miyake et al., 2014). RNA-seq analysis shows FGF16 is expressed during gastrulation in $X$.laevis and $X$.tropicalis embryos (Owens et al., 2016; Session et al., 2016). For example, FGF16.L expression peaks at NF stage 12 and remains high during neurulation in X.laevis, before decreasing in early and late tailbud stages, whereas FGF16.S is expressed at a much lower level, and is not expressed after gastrulation (Owens et al., 2016; Session et al., 2016). Attempts to clone FGF16 from Xenopus tropicalis were unsuccessful (Lea et al., 2009), and the spatial expression pattern of FGF16 has not been previously described during the development of $X$.tropicalis or X.laevis.

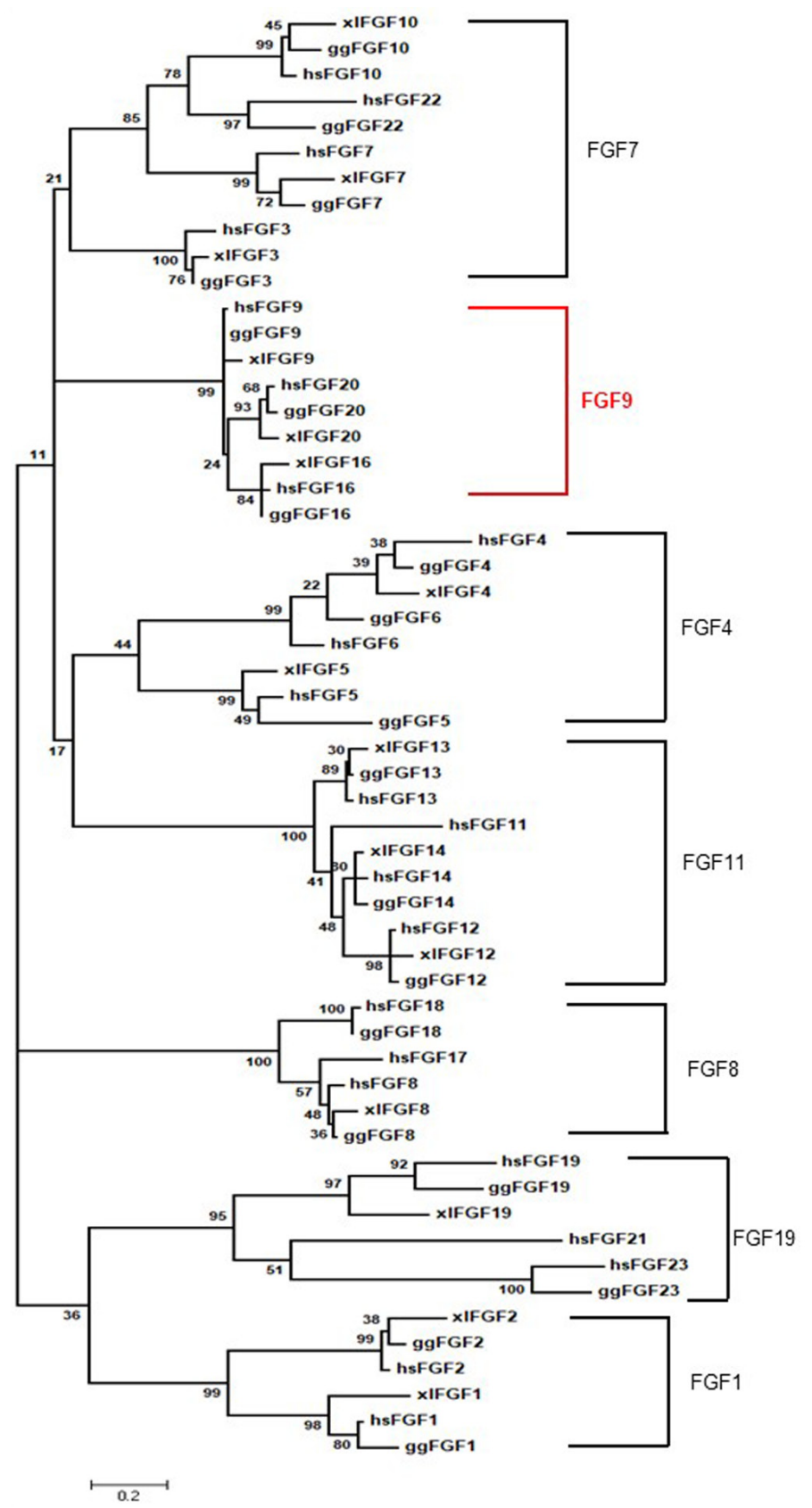

TABLE 1

PRIMER SEQUENCES (5' TO 3')

\begin{tabular}{lll}
\hline cdx4 & Forward & GGGAGGAATGGAACTCTTATGG \\
& Reverse & TGTACCGCAGAGTCACAAAG \\
Egr1 & Forward & TCGATCACCTAACAGCAGATG \\
& Reverse & GGTAGTCTTTGAGACAGGGTATG \\
Xbra & Forward & GAGCCCACTGGATGAAAGAT \\
& Reverse & AGCATGTGAAAGAGACGAGTAG \\
rpl8 & Forward & GGGCTRTCGACTTYGCTGAA \\
& Reverse & ATACGACCACCWCCAGCAA \\
Sp5 & Forward & GCTGTCCTAAGGAATGACTCTC \\
& Reverse & CTGCACAGAGAGAACACACTT \\
Sp5I & Forward & ACCTGCATCTTCTGCATCTC \\
& Reverse & GCCTGAAGATGACAGATATGG \\
FGF16 & Forward & ATGGCTGAGATTGGGAGCGTT \\
& Reverse & TCACCTATAGTGATAAAGATC \\
\hline
\end{tabular}

Transcription downstream of FGF signalling has been investigated in Xenopus mesoderm (Branney et al., 2009) and the genetic targets identified included sp5 and sp5-like (sp5I), which code for zinc finger transcription factors (Ossipova et al., 2002). Despite this finding in Xenopus, most of the knowledge linking sp5 and sp5/ to a role downstream of FGF signalling comes from work in zebrafish. Sp5 (bts 1) expression in the neural plate was found to be strongly reduced in response to FGF inhibition (Tallafu $\beta$ et al., 2001), and sp5I expression in the mesoderm is also dependent on the presence of FGF signals (Zhao et al., 2003; Weidinger et al., 2005). Consistent with a role downstream of FGF signalling, Sp5I can posteriorize the neuroectoderm, as it positively regulates posterior neuroectodermal marker hoxb1b and represses the anterior markers fez and otx1 in whole embryos (Zhao et al., 2003). These studies support the idea that sp5 and sp5/ are downstream targets of FGF signalling in zebrafish. Here we describe the cloning and characterisation of $X$. laevis FGF16 and identify sp5 and sp5/ as transcriptional targets of FGF signalling during amphibian development.

\section{Results}

\section{Cloning of Xenopus laevis FGF16}

The predicted sequence for $X$. laevis FGF16 on chromosome 8L encodes a 202 amino acid protein that is highly homologous $(86 \%$ amino acid identity) to human FGF16. The genomic organisation shows syntenic regions in Xenopus and human chromosomes, providing confidence that the sequence (GenBank Accession No. XM_018229763.1) encodes for the full-length $X$. laevis FGF16.L protein. PCR primers were designed against the predicted CDNA sequence (Table 1) and a 609bp product was amplified from cDNA derived from $X$. laevis embryos (NF stage 11).

Fig. 1. Phylogenetic analysis of predicted FGF families. FGF family groupings are represented by brackets. Bold red brackets indicate the FGF9 subfamily: FGF9, FGF16 and FGF20. Protein sequences were aligned using MUSCLE. The evolutionary history was inferred by using the Maximum Likelihood method based on the Jones-Taylor-Thornton (JTT) matrix-based model (Jones et al., 1992). The percentage of trees in which the associated taxa clustered together is shown next to the branches $(500$ bootstrap support). The tree is drawn to scale, with branch lengths measured in the number of substitutions per site. Labels are as follows: $X I$ =Xenopus laevis; $g g=$ Gallus gallus; $h s=$ Homo sapiens . 


\section{Analysis of gene expression at gastrula stages}

DIG-labelled antisense RNA probes were used for in situ hybridisation analysis of FGF16 gene expression (Figs 2 and 3). FGF16 expression is restricted to the dorsal blastopore lip during stage 10, and as gastrulation proceeds, the expression of FGF16extends to the mesoderm around the whole of the blastopore by stage 11 and is seen in the posterior mesoderm around the closed blastopore at stage 12 . We have analysed the genes sp5 and sp5/ as potential targets of FGF signalling; at gastrula stages, both sp5 and sp5/ have much wider expression domains than FGF16 (Fig. 2 D-E and G-H). At NF stage 12, FGF16, sp5 and $s p 5 /$ are all co-expressed in the posterior mesoderm around the closed blastopore (Fig. 2 C, F, and I; arrow).

\section{Analysis of FGF16 at later stages}

Using in situ hybridisation we have found that FGF16 is expressed in the posterior mesoderm of early tailbud embryos, as well as the otic vesicle and anterior pituitary (Fig. 3A,B). FGF16 expression is detected in the branchial arches and mesoderm of later tailbuds (Fig. 3C,D). In the tail, FGF16 expression is restricted to the chordoneural hinge and the posterior wall of the neuroenteric canal (Fig. 3D) (Tucker \& Slack, 1995). FGF16 is expressed in the anterior pituitary during early tailbud development (Fig. 3B) in X.laevis, consistent with findings in zebrafish (Miyake et al., 2014).

\section{Analysis of sp5 and sp5I in X.tropicalis embryos}

The expression of $s p 5$ and $s p 5 /$ has been described in $X$. laevis, but not in $X$. tropicalis, which we report here (Ossipova et al., 2002). Sp5 expression in $X$. tropicalis at neurula stage 18 is found in the midbrain and the neural crest, as well as being faintly expressed towards the posterior of the embryo (Fig. 4 A-B). Sp5/ is expressed along the neural folds and in the posterior region of the embryo (Fig. 4 D-F) and also expressed in migrating crest cells in the branchial arch region (Fig. 4 D). At stage 25, early tailbud, sp5 has clear expression in the head, including the forebrain, midbrain, midbrain-hindbrain barrier (MHB) and otic placode, but also in a small domain in the tailbud (Fig. 4 C). Sp5/ at stage 26 is expressed in the posterior of the neural tube and the tailbud, but also in a small domain in the head (Fig. 4G-H). At stage 31, sp5 expression in $X$. tropicalis is found in the forebrain, midbrain, MHB, branchial arches (BA) 1-4 as previously described in X.laevis (Square et al., 2015), and dorsal to the otic vesicles and in the tailbud (Fig. $4 \mathrm{I}-\mathrm{K}$ ). At this stage, $s p 5 /$ is only expressed in the tailbud (Fig. 4 L-M). These data reveal that the expression patterns of $s p 5$ and $s p 5 /$ are distinct throughout development and have

Fig. 3. Developmental expression pattern of FGF16 in X.laevis embryos. In situ hybridisation analysis was used to detect transcripts for FGF16 at several developmental stages in $X$. laevis embryos. At least 15 embryos were analysed at each stage (st). (A,B) St 26, lateral and anterior views respectively. (C,D) St 35, lateral and magnified lateral tail views respectively. Abbreviations are as follows: anterior pituitary (ap), otic vesicle (ov), plate mesoderm (pm), branchial arches (ba) and chordoneural hinge (cnh)
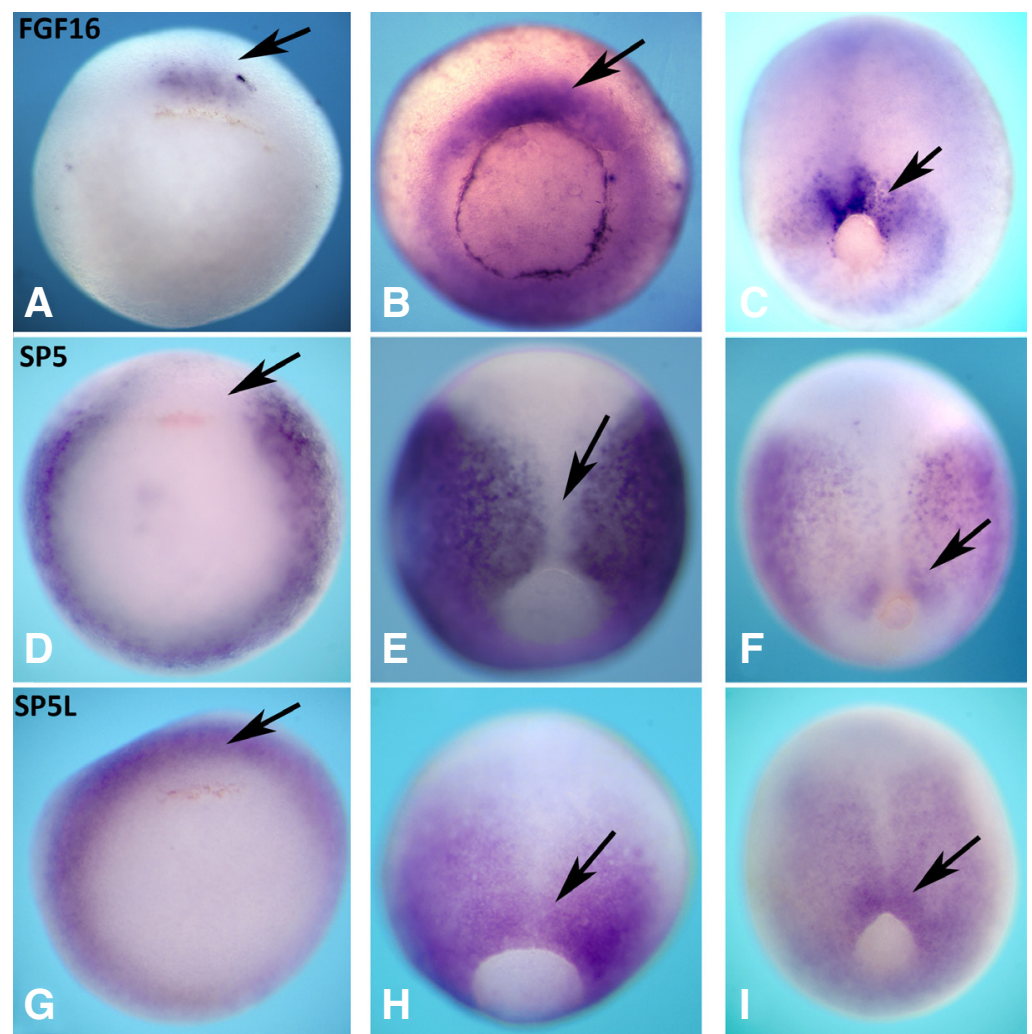

Fig. 2. Expression analysis FGF16, sp5 and sp5I in gastrula stage $X$.laevis embryos. In situ hybridisation analysis was used to detect transcripts for FGF16 (A-C), sp5 (D-F), and sp5/ (G-I) during gastrulation. Stages 10 posterior/vegetal $(A, D, G)$ 11 posterior/vegetal view $(B, E, H)$ and $12(C, F, I)$ posterior view. Arrow indicates dorsal blastopore lip in all panels.

some overlapping regions of expression to FGF16, as well as other FGF ligands (Lea et al., 2009).

\section{Analysis of FGF16 signal transduction}

The $\mathrm{N}$-terminus of most FGF ligands has a region of high hydrophobicity called a signal sequence that is required for secretion. However, vertebrate orthologues of FGF9, FGF16 and FGF20
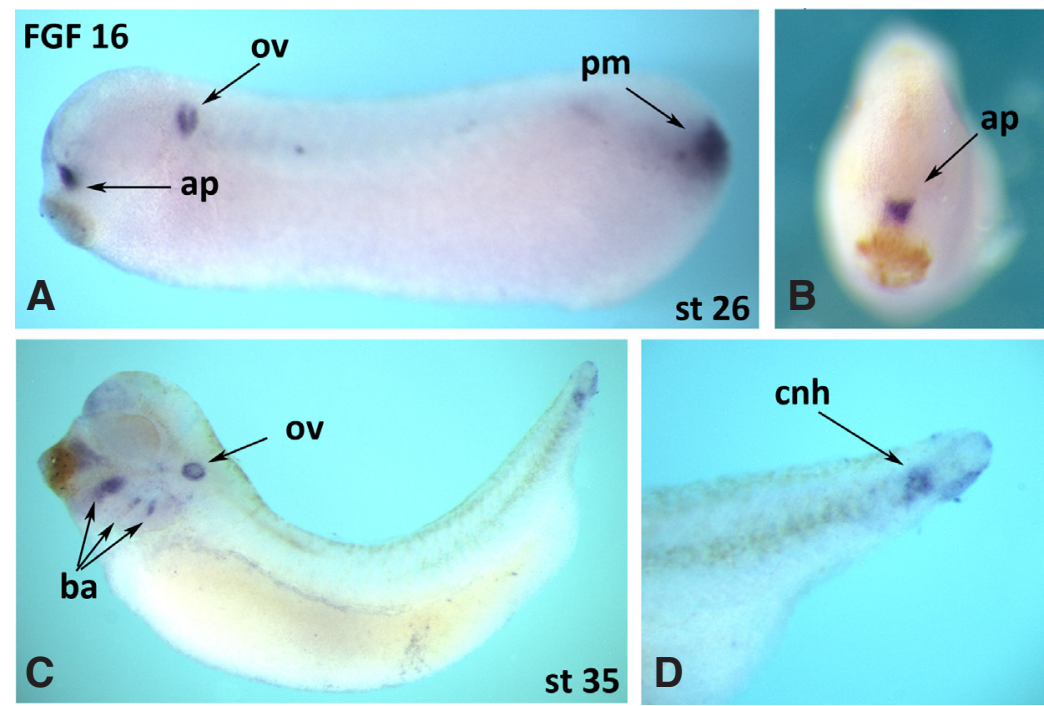

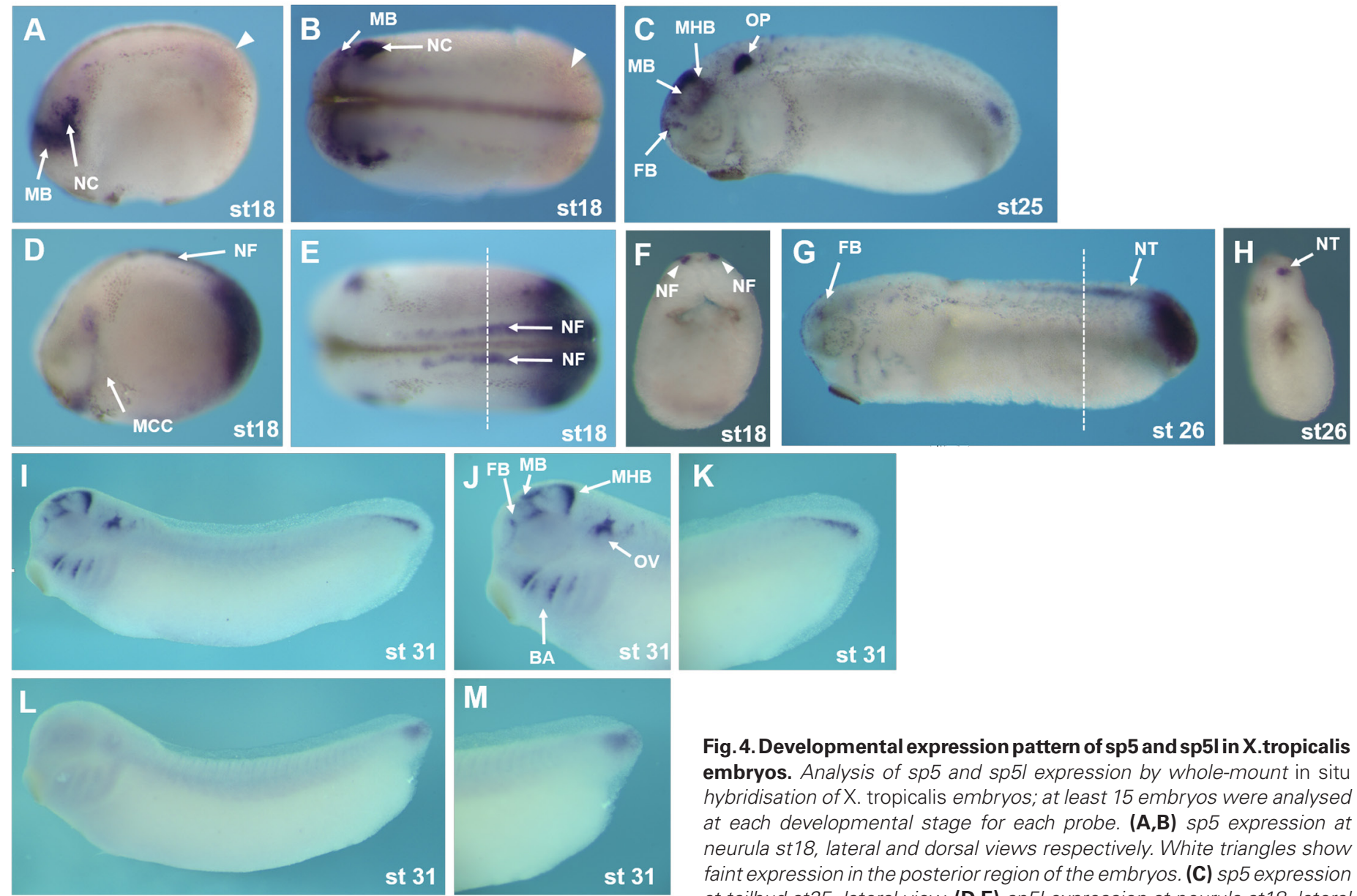

Fig. 4. Developmental expression pattern of sp5 and sp5I in X.tropicalis embryos. Analysis of sp5 and sp5I expression by whole-mount in situ hybridisation of X. tropicalis embryos; at least 15 embryos were analysed at each developmental stage for each probe. $(\mathbf{A}, \mathbf{B})$ sp5 expression at neurula st18, lateral and dorsal views respectively. White triangles show faint expression in the posterior region of the embryos. (C) sp5 expression at tailbud st25, lateral view. (D,E) sp5l expression at neurula st18, lateral and dorsal views respectively. (F) Transverse section of the embryo in (E) at the level of the dashed line. (G) sp5/ expression at tailbud st26, lateral view. (H) Transverse section of embryo in (G) at the level of the dashed line. (I-K) sp5 expression at tailbud st31, lateral view. (L,M) sp5I expression at tailbud st31, lateral view. Abbreviations: Midbrain (MB), Neural crest (NC), Forebrain (FB), Otic placode (OP), Midbrain Hindbrain Boundary (MHB), Migrating crest cells (MCC) Neural fold (NF), Neural tube (NT), Branchial Arches (BA), Otic Vesicle (OV).

have divergent $\mathrm{N}$-termini and lack a signal sequence (Miyakawa \& Imamura, 2003). These FGF ligands are characterised by conserved mid-regions and C-terminithat allow secretion (Katoh \& Katoh, 2005). This is shown in Fig. 5, where the low N-terminus hydrophobicity for the FGF9 subfamily is compared to FGF4 (Fig. 5A, compared to Fig. 5 B-D). The FGF9 subfamily members contain an internal hydrophobicity region, which likely aids the proteins' secretion out of the cell (Miyakawa \& Imamura, 2003).

The animal cap is a source of pluripotent cells which develops into atypical epidermis in the absence of additional signals (Green, 1999). Upon treatment with growth factors, including FGFs, the animal cap can be diverted from this epidermal fate to differentiate into different tissue types, such as mesoderm (Kimelman \& Kirschner, 1987; Slack et al., 1987). Therefore, this approach provides a robust biological assay for FGF16 activity (Fig. 6). ERK, also known as MAPK, is the effector of the Ras-Raf-MEK-MAPK signalling pathway. The diphosphorylation of ERK (dp-ERK) indicates that FGF16 can strongly activate the MAPK signalling pathway in animal caps (Fig. 6A). FGF16 is shown to affect cell behaviour, due to untreated animal caps forming round balls of atypical epidermis after 3 days (Fig. 6B), whereas those expressing FGF16 form vesicles of mesoderm including blood, mesothelium and muscle (Fig. 6C).

\section{FGF signalling activates sp5 and sp5I expression}

Previous research suggests that $X$.laevis sp5 and sp5/ are positively regulated targets of FGF signalling (Branney et al., 2009; Park et al., 2013). To further test this possibility, the effect of increasing FGF signalling on sp5 and sp5/ expression was investigated. $X$. laevis embryos were injected with 10pg of mRNA coding for FGF4, known to be a potent mesoderm inducer (Isaacs et al., 1994), or $50 \mathrm{pg}$ of mRNA coding for FGF16. RT-PCR was performed on stage 12 whole embryos and animal cap explants from injected embryos compared to uninjected controls. Expression of sp5, sp5l and known FGF targets, $x b r a, c d x 4$, and gr1, was analysed. Both FGF4 and FGF16 injection induced the FGF target genes as well as sp5 and sp5l (Fig. 6D).

Collectively these results show that sp5and sp5/are downstream targets of FGF signalling, with the identification of FGF16 as a novel ligand that has mesoderm inducing activity.

\section{Discussion}

\section{FGF16 signal transduction}

In this study, FGF16 was found to be able to activate MAPK signalling and induce mesoderm. The Ras-Raf-MEK-ERK(MAPK)- 
Fig. 5. Hydrophobicity plots for FGF9 family. Kyte and Doolittle hydrophobicity plots for (A) FGF4 and FGF9 sub-family members, (B) FGF9, (C) FGF16, and (D) FGF20. Scores above 0 (represented by the dotted line) indicate hydrophobic amino acids; sites of high hydrophobicity are depicted as shaded areas. FGF4 has a "classic" signal sequence (SS) for co-translational secretion, but the members of the FGF9 subfamily have an internal hydrophobicity region which is associated with secretion.
A

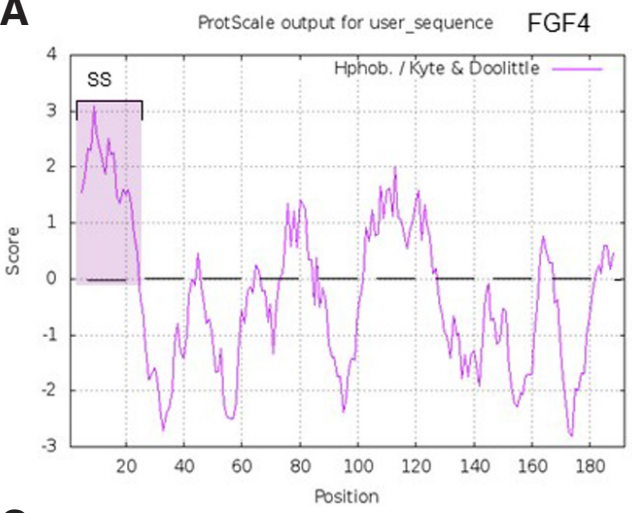

C

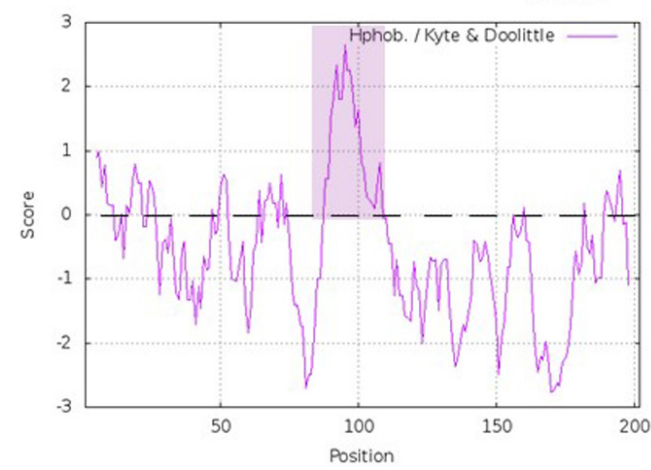

B

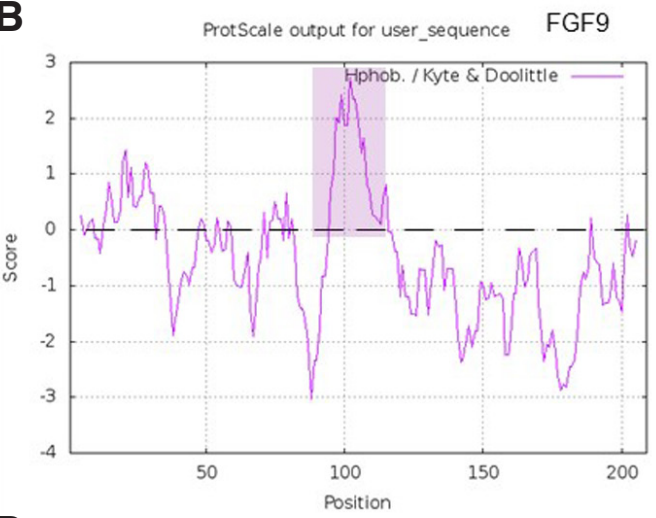

D

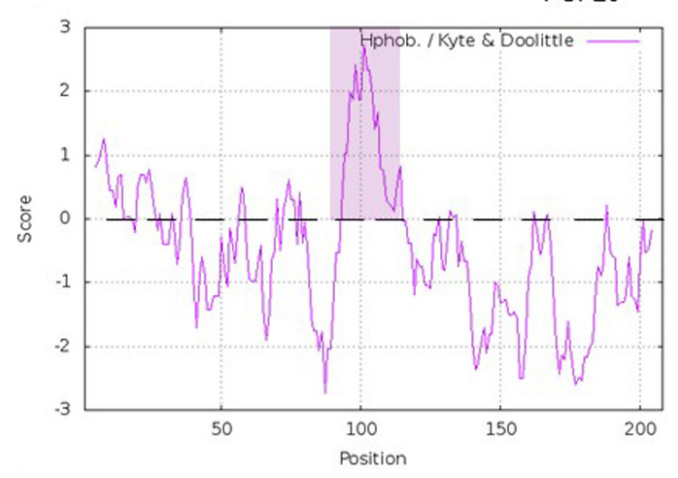

pathway has a well-defined role in regulating mesoderm induction in response to FGF signalling (Cornell \& Kimelman, 1994; LaBonne et al., 1995; LaBonne \& Whitman, 1994; Umbhauer et al., 1995; Whitman \& Melton, 1992). FGF16 has also been shown to signal through the MAPK pathway in human ovarian cancer cells (Basu et al., 2014), and here we demonstrate FGF16-mediated MAPK activity to be observed in the mesoderm induction assay. The role of FGF9, FGF16 and FGF20 in mesoderm induction has not been well characterised. However, FGF9/16/20, an ancestral form of the vertebrate FGF9 subfamily, has been shown to induce mesenchyme formation in Ciona intestinalis embryos (Imai et al., 2002; Tokuoka et al., 2004). The presence and activity of this class of FGF ligand in a distant chordate relative supports the notion that $F G 9 / 16 / 20$ is a conserved factor for mesoderm specification (Davidson et al., 2006). Furthermore, an RNA-seq screen of $X$. laevis gastrula expression in dorsal and ventral lip tissue identified FGF16.S and FGF16. L as having moderate positive Pearson correlation coefficients of 0.48 and 0.25 respectively to chordin, indicating the two genes may share transcriptional regulation mechanisms and that FGF16 may be involved in dorsal-ventral patterning (Ding et al., 2017).

The paracrine FGFs signal through the four different FGFRs, triggering multiple downstream signalling pathways to result in the regulation of transcription factors required for controlling many different developmental processes, such as mesoderm induction (reviewed in Ornitz and Itoh, 2015). The alternative splicing of FGFR receptors greatly increases ligand binding specificity, particularly through the generation of two isoforms of Ig-like domain III (epithelial b splice forms or mesenchymal c splice forms) (Yeh et al., 2003). FGF9 subfamily members have similar FGFR binding affinities (Zhang et al., 2006). For example, mouse homologue
FGF9 preferentially binds to FGFR2 and FGFR3 c splice variants, displaying greatest affinity for FGFR3, but does not bind FGFR1 or FGFR4 (Hecht et al., 1995; Ornitz et al., 1996; Santos-Ocampo et al., 1996). Zhang et al., (2006) confirm a strong binding of FGF9, 16 and 20 to FGFR3c, FGFR3b and FGFR2c when cataloguing the receptor binding of all FGF ligands in the murine Baf3 cell line. FGF20 binding matches the other FGF9 subfamily members, although it has higher affinity for FGFR2b (Zhang et al., 2006). Murine FGF16 appears to have the highest affinity for FGFR3c, followed by FGFR3b and FGFR2c, but does not bind to FGFR2b or FGFR1b and only weakly binds FGFR4 (Zhang et al., 2006). The same binding profile for FGF16 is revealed using the Baf3 assay, with very weak FGFR1c affinity demonstrated (Lavine et al., 2005; Lu et al., 2008). Furthermore, FGF16-mediated invasion in a human ovarian cancer model persists upon addition of a selective FGFR1 inhibitor, PD 173074 (Mohammadi et al., 1998), confirming FGF16 to not preferentially signal through FGFR1 (Basu et al., 2014). Konishi et al., (2000) also report that FGF16 only binds the extracellular domain of FGFR4, showing no affinity for FGFR1c or FGFR2c, during embryonic brown adipose tissue development, suggesting altered FGF16 ligand specificity for different developmental stages or tissue types.

\section{FGF16 secretion}

Phylogenetic analysis of sequences obtained from Xenbase matched the consensus arrangement of the 22 FGF members into 7 different subfamilies (Fig. 1) (Itoh \& Ornitz, 2004). FGF9 subfamily members are highly homologous in structure and have similar receptor binding sites (Itoh \& Ornitz, 2004; Zhang et al., 2006). For example, they have a conserved C-terminus and central hydrophobic region, which is required for secretion (Miyakawa \& 
Imamura, 2003). Despite this knowledge, the mechanism of FGF16 secretion remains to be elucidated.

Most FGFs require $\mathrm{N}$-terminal signal peptides for secretion (Kapp etal., 2009). However, FGF1, FGF2, FGF9, FGF16 and FGF20 lack cleavable signal peptides. FGF1 and 2 can be released in response to damage via an ER-Golgi independent exocytotic secretory pathway (Itoh \& Ornitz, 2004; Mignatti et al., 1992). Instead, FGF2 directly translocates across the plasma membrane for secretion (Nickel, 2010; Zehe et al., 2006). Although FGF9 subfamily members are secreted, they reply upon uncleavable bipartite signals including the $\mathrm{N}$-terminal and central hydrophobic region (Miyakawa et al., 1999; Revest et al., 2000). Interestingly, Miyakawa \& Imamura (2003) showed that FGF16 is secreted by a process requiring the endoplasmic reticulum and Golgi; retrograde Golgi transport of FGF16 was first inhibited by using brefeldin $\mathrm{A}$ and $\mathrm{N}$-glycosylation of the N-terminus was separately observed, indicating that FGF16 must have progressed to the ER for processing.

\section{sp5 and sp5I expression and regulation}

Our data indicate that sp5and sp5/are candidates for regulation by FGF16. There is overlap of their expression domains in the early mesoderm and FGF16 is able to activate the expression of both sp5 and sp5/in a mesoderm induction assay. Compared to its relatives, $s p 5$ is unique having two paralogs in the Xenopus and teleost lineages (Ossipova et al., 2002; Zhao et al., 2003, Tallafu $\beta$ et al., 2001), whilst there is only one locus present in mammals (Harrison et al., 2000). Phylogeny suggests that these genes were duplicated from the same ancestor, but one copy was lost subsequently from the mammalian and bird lineages in evolution (Zhao et al., 2003; Pei and Grishin, 2015). In Xenopus these paralogs are referred to as sp5 and sp5I.

The Sp1-like transcription factors are a family of proteins with important regulatory roles in development (Reviewed by Zhao and Meng., 2005). The family comprises of Sp1 along with a number of structurally similar transcription factors which share defining features such as a triple $\mathrm{C}_{2} \mathrm{H}_{2}$ zinc finger domain in the $\mathrm{C}$-terminal region and a preceding buttonhead (Btd) box (Reviewed by Zhao and Meng, 2005; Ossipova et al., 2002). Sp1-like transcription factors have been identified in a variety of species, including Xenopus, which has 10 members (Presnell et al., 2015). These transcription factors regulate the expression of target genes by acting as transcriptional activators or repressors in a contextdependent manner (Fujimura et al., 2007; Hagen et al., 1995; Birnbaum et al., 1995; Phan et al., 2004; Majello et al., 1997). The DNA binding specificity of these factors is similar across the family, with the conserved triple zinc finger domain recognising GC-rich sequences in the promoter regions of genes (Kadonaga et al., 1987). Differences in key residues of the zinc finger motifs modulate this DNA binding specificity between family members (Reviewed by Kaczynski et al., 2003). Although this family shares commonality in structure and DNA binding, different members appear to play distinct roles in embryonic development, which is demonstrated by their dynamic expression patterns (Reviewed by Zhao and Meng, 2005). In situ hybridisation in Xenopus species showed that sp5 and sp5/ have distinct expression patterns throughout development.

Sp5 and sp5l clearly have differential expression patterns throughout development, indicating they likely have different functional roles. Presence of $s p 5$ in the neural crest and related structures, the branchial arches and otic vesicle, suggests a role in neural crest formation. Supporting this hypothesis, knockdown of $s p 5$ results in defective neural crest structures and sp5 overexpression or loss causes up- or down-regulation of neural crest markers sox10, sox9 and slug (Park et al., 2013). Sp5/expression is similar to posterior factors $c d x 4$ and hoxA7, with expression in the posterior neural tube and tailbud (Northrop and Kimelman, 1993; Pownall et al., 1998) suggesting a role in posterior patterning.

In comparison to Xenopus, murine Sp5 is expressed in the primitive streak throughout gastrulation and is subsequently in the midbrain, $\mathrm{MHB}$, neural tube, somites, pharyngeal region and the tailbud (Harrison et al., 2000). Xenopus sp5 and sp5l recapitulate different aspects of mammalian Sp5 patterning and possibly function. Murine Sp5and Xenopus sp5 share expression in the midbrain, MHB and pharyngeal region, whereas Xenopus sp5I and murine Sp5 share expression in the neural tube. Both 
Xenopus paralogs are expressed in the tailbud, like murine Sp5. Mammals do not possess Sp5I, hence mammalian Sp5 may perform the roles of both Xenopus sp5 and sp5I. This suggests a divergence of function in Xenopus Sp5 and Sp5I proteins after their duplication event, whilst mammals lost their Sp5/locus and Sp5 retained all function.

\section{Materials and Methods}

\section{Embryos}

$X$. laevis and Xenopus tropicalis embryos were obtained using artificial fertilisation. X.laevis embryos were microinjected in $0.3 \times$ normal amphibian medium (NAM) $+5 \%$ ficoll and cultured in $0.1 \times$ NAM between temperatures of $14^{\circ} \mathrm{C}-23^{\circ} \mathrm{C}$. X.tropicalis embryos were cultured in MRS/20 between temperatures $20^{\circ} \mathrm{C}-24^{\circ} \mathrm{C}$. All embryos were staged according to Nieuwkoop \& Faber (1967).

\section{Multiple sequence alignments for FGF16}

Xenbase was used to obtain the available $X$. laevis FGF amino acid and coding sequences (Karimi et al., 2018). BLAST (Basic Local Alignment Search Tool) searches identified the Gallus gallus (chick) and Homo sapiens (human) FGF sequences (Priyam et al., 2015). X. laevis FGF16 is unavailable on Xenbase; the human FGF16 amino acid sequence was used to identify the $X$. laevis FGF16 genomic sequence. The apparent evolutionary relationship between all members of the $X$. laevis, Gallus gallus and Homo sapiens FGF families was examined. A maximum-likelihood phylogenetic tree was created using Mega7 software and alignments performed for amino acid sequences using MUSCLE (Edgar, 2004; Kumar et al., 2016). FGF9, FGF16 and FGF20 alignments were created using GeneDoc software (Nicholas, 1997).

\section{Cloning of Xenopus laevis FGF16}

RNA was extracted from stage $11,17,20$ and $25 X$. laevis embryos via Trizol (Invitrogen) extraction and the Zymo-Spin ${ }^{\mathrm{TM}}$ IC column RNA preparation procedure (Zymo Research), according to the manufacturer's instructions. Extracted RNA was used to generate cDNA using the SuperScript ${ }^{\circledR}$ IV First-Strand Synthesis System (Invitrogen). Stage 11 cDNA was amplified by polymerase chain reaction (PCR) with GoTaq® Green Master Mix (Promega) and specific FGF16 primers (Table 1). PCR products were ligated into the pGEM-T Easy DNA vector (Promega), and subsequently subcloned into pCS2+ using EcoR1.

\section{In vitro transcription of DIG-labelled probes}

pGEM-FGF16 was linearized using Sph1; pCS107 containing Sp5 (GenBank Accession: AAH62500) using Ncol, and pCS107 containing Sp5I (GenBank Accession: AAI54679) using Hindlll before transcription using the DIG RNA Labelling Kit (Roche). T7 RNA polymerase was used for sp5 and sp5/DIG transcription and SP6 RNA polymerase for FGF16.

\section{In situ hybridisation}

Embryos were collected at the appropriate stages and fixed in MEMFA (0.1M MOPS, 2mM EDTA, $1 \mathrm{mM} \mathrm{MgSO}_{4}, 3.7 \%$ formaldehyde). In situ hybridisations were performed following the procedure described in Fisher et al., (2002). Hybridisation was carried out overnight at $60^{\circ} \mathrm{C}$ with $1 \mu \mathrm{g} /$ $\mathrm{ml}$ of FGF8- and FGF16- DIG probes. Embryos were then incubated overnight at $4^{\circ} \mathrm{C}$ with a $1 / 2000$ dilution of affinity-purified sheep anti-DIG antibody coupled to alkaline phosphatase (AP) in blocking solution. Colour reactions were subsequently performed overnight using the BM purple precipitating AP detection system (Roche). Pigment was removed using $5 \% \mathrm{H}_{2} \mathrm{O}_{2}$ solution in PBS.

\section{Photography}

Images were taken using the SPOT insight 4 MP CCD colour camera attached to a Leica MZFLIII microscope.

\section{Generating synthetic mRNA}

pCS2+-FGF16 was linearized using Notl and Capped FGF16 mRNA was generated using the mMessage mMachine SP6 transcription kit (Invitrogen), following the manufacturer's instructions.

\section{Western blot analysis}

$X$. laevis animal cap explants were dissected at NF stage 8 and cultured until NF stage 12 when they were collected and homogenised in sample buffer and centrifuged (Keenan et al., 2006). Supernates were loaded onto an acrylamide gel for SDS-PAGE and protein electro-transferred onto Immobilon-PPDVF membranes (Millipore). Membranes were blocked in 5\% milk/PBSAT. Primary antibody dilutions were: mouse $\alpha$-dp-ERK (Sigma), 1/4000; $\alpha$-total-ERK, 1/500,000; $\alpha$-pP38, 1/2000; $\alpha$-pAKT, 1/5000. Secondary antibody dilutions were: dpERK $\alpha$-mouse HRP, 1/4000; total ERK, pP38 and pAKT $\alpha$-rabbit, 1/2000. BM chemiluminescence blotting substrate (Roche) was used for peroxidase activity detection.

\section{Semi-quantitative RT-PCR}

5 embryos, or 10 animal cap (ectodermal) explants, were flash-frozen on dry ice, and RNA was extracted using TRIzol Reagent ${ }^{\circledR}$ (Sigma). cDNA was synthesised from $1 \mu \mathrm{g}$ of total RNA using SuperScript ${ }^{\circledR}$ IV Reverse Transcriptase (Invitrogen). In short, total RNA was incubated for 5 mins at $65^{\circ} \mathrm{C}$ with $50 \mu \mathrm{M}$ random hexamer primers and then incubated with reverse transcriptase at $23^{\circ} \mathrm{C}$ for $10 \mathrm{mins}, 55^{\circ} \mathrm{C}$ for $10 \mathrm{mins}$ and $80^{\circ} \mathrm{C}$ for 10 mins. To check for any genomic contamination, control RNA was also processed without reverse transcriptase. PCR amplification was performed using primers in Table 1, including those for ribosomal protein $L 8$ (rp/8) as a ubiquitously expressed loading control.

\section{Acknowledgements}

$M E, A R$ and $H L$ undertook this work as part of their undergraduate research projects at the University of York.

\section{References}

BASU M, MUKHOPADHYAY S, CHATTERJEE U, ROY SS (2014). FGF16 promotes invasive behavior of SKOV-3 ovarian cancer cells through activation of mitogenactivated protein kinase (MAPK) signaling pathway. J Biol Chem 289: 1415-1428.

BELIN D, BOST S, VASSALLI JD, STRUB K (1996). A two-step recognition of signa sequences determines the translocation efficiency of proteins. EMBOJ15:468-478.

BELLAIRS, R. AND OSMOND M (2005). Atlas of chick development. Elsevier.

BELLOVINO D, MORIMOTO T, MENGHERI E, PEROZZI G, GARAGUSO I, NOBILI F, GAETANI S (2001). Unique biochemical nature of carp retinol-binding protein. $\mathrm{N}$-linked glycosylation and uncleavable $\mathrm{NH} 2$-terminal signal peptide. J Biol Chem 276: 13949-13956.

BIRNBAUM MJ, VAN WIJNEN AJ, ODGREN PR, LAST TJ, SUSKE G, STEIN GS, STEIN J. (1995). Spl Trans-Activation of Cell Cycle Regulated Promoters Is Selectively Repressed by. Biochemistry 34: 16503-16508.

BRANNEY PA, FAAS L, STEANE SE, POWNALLME, ISAACS H V. (2009). Characterisation of the fibroblast growth factor dependent transcriptome in early development. PLoS One 4(3):e4951. doi: 10.1371/journal.pone.0004951. Epub 2009 Mar 31.

CHAPMAN SC, CAI Q, BLEYL SB, SCHOENWOLF GC (2006). Restricted expression of FGF16 within the developing chick inner ear. Dev Dyn 235: 2276-2281.

CORNELL RA, KIMELMAN D (1994). Activin-mediated mesoderm induction requires FGF. Trends Genet 10: 150.

DAVIDSON B, SHI W, BEH J, CHRISTIAEN L, LEVINE M (2006). FGF signaling delineates the cardiac progenitor field in the simple chordate, Ciona intestinalis. Genes Dev 20: 2728-2738.

DING Y, COLOZZA G, ZHANG K, MORIYAMA Y, PLOPER D, SOSA EA, BENITEZ MDJ, DE ROBERTIS EM (2017). Genome-wide analysis of dorsal and ventral transcriptomes of the Xenopus laevis gastrula. Dev Biol 426: 176-187.

DOREY K, AMAYA E (2010). FGF signalling: diverse roles during early vertebrate embryogenesis. Development 137: 3731-3742.

EDGAR RC (2004). MUSCLE : a multiple sequence alignment method with reduced 
time and space complexity. BMC Bioinformatics 5: 113.

FISHER ME, ISAACS H V, POWNALL ME (2002). eFGF is required for activation of XmyoD expression in the myogenic cell lineage of Xenopus laevis. Development 129: 1307-1315.

FUJIMURA N, VACIK T, MACHON O, VLCEK C, SCALABRIN S, SPETH M, DIEP D, KRAUSS S, KOZMIK Z (2007). Wnt-mediated down-regulation of Sp1 target genes by a transcriptional repressor Sp5. J Biol Chem 282: 1225-1237.

GOETZ R, MOHAMMADI M (2013). Exploring mechanisms of FGF signalling through the lens of structural biology. Nat Rev Mol Cell Biol 14: 166-180.

GREEN J (1999). The animal cap assay. In Molecular methods in developmental biology: Xenopus and zebrafish pp. 1-13.

HAGEN G, PREISS A, BEATO M, SUSKE G (1995). Functional analyses of the transcription factor Sp4 reveal properties distinct from Sp1 and Sp3. J Biol Chem 270: 24989-24994.

HARRISON SM, HOUZELSTEIN D, DUNWOODIE SL, BEDDINGTON RSP (2000). $\mathrm{Sp5}$, a new member of the Sp1 Family, is dynamically expressed during development and genetically interacts with Brachyury. Dev Biol 227: 358-372.

HECHT D, ZIMMERMAN N, BEDFORD M, AVIVI A, YAYON A (1995). Identification of fibroblast growth factor 9 (FGF9) as a high affinity, heparin dependent ligand for FGF receptors 3 and 2 but not for FGF receptors 1 and 4 . Growth Factors 12: 223-233.

HOTTAY, SASAKI S, KONISHI M, KINOSHITAH, KUWAHARAK, NAKAO K, ITOH N (2008). FGF16 is required for cardiomyocyte proliferation in the mouse embryonic heart. Dev Dyn 237: 2947-2954.

IMAI KS, SATOH N, SATOU Y (2002). Early embryonic expression of FGF4 / 6 / 9 gene and its role in the induction of mesenchyme and notochord in Ciona savignyi embryos. Development 1738: 1729-1738.

ISAACS H V., POWNALL ME, SLACK JMW (1995). eFGF is expressed in the dorsal midline of Xenopus laevis. Int J Dev Biol 39: 575-579.

ISAACS H V, POWNALL ME, SLACK JM (1994). eFGF regulates Xbra expression during Xenopus gastrulation. EMBO J 13: 4469-81.

ITOH N, ORNITZ DM (2004). Evolution of the FGF and FGFr gene families. Trends Genet 20: 563-569.

JOHNSON DE, LU J, CHEN H, WERNER S (1991). The human fibroblast growth factor receptor genes : a common structural arrangement underlies the mechanisms for generating receptor forms that differ in their third immunoglobulin domain. $\mathrm{Mol}$ Cell Biol 11: 4627-4634.

KACZYNSKI J, COOK T, URRUTIA R (2003). Sp1- and Krüppel-like transcription factors. Genome Biol 4: 1-8.

KADONAGA JT, CARNER KR, MASIARZ FR, TJIAN R (1987). Isolation of cDNA encoding transcription factor Spl and functional analysis of the DNA binding domain. Cell 51: 1079-1090.

KÄLLL, KROGHA, SONNHAMMERELL(2004). Acombined transmembrane topology and signal peptide prediction method. J Mol Biol 338: 1027-1036.

KAPP K, LEMBERG MK, DOBBERSTEIN B (2009). Post - targeting functions of signal peptides. In: Protein Transport into the Endoplasmic Reticulum. (R. Zimmermann, ed.). Landes Bioscience

KARIMI K, FORTRIEDE JD, LOTAY VS, BURNS KA, WANG DZ, FISHER ME, PELLS TJ, JAMES-ZORN C, WANG Y, PONFERRADA VG, CHU S, CHATURVEDI P, ZORN AM, VIZE PD (2018). Xenbase: a genomic, epigenomic and transcriptomic model organism database. Nucleic Acids Res 46: D861-D868.

KATOH, Y. AND KATOH M (2005). Comparative genomics on FGF16 orthologs. Int $J$ Mol Med 16: 959-963.

KEENAN ID, SHARRARD RM, ISAACS H V. (2006). FGF signal transduction and the regulation of Cdx gene expression. Dev Biol 299: 478-488.

KIMELMAN D, KIRSCHNER M (1987). Synergistic induction of mesoderm by FGF and TGF- $\beta$ and the identification of an mRNA coding for FGF in the early Xenopus embryo. Cell 51: 869-877.

KONISHI M, MIKAMI T, YAMASAKI M, MIYAKE A, ITOH N (2000). Fibroblast growth factor-16 is a growth factor for embryonic brown adipocytes. J Biol Chem 275: 12119-12122.

KUMAR S, STECHER G, TAMURA K (2016). MEGA7 : Molecular Evolutionary Genetics Analysis Version 7. 0 for Bigger Datasets. Mol Biol Evol 33: 1870-1874.

LABONNE C, BURKE B, WHITMAN M (1995). Role of MAP kinase in mesoderm induction and axial patterning during Xenopus development. Development 121:
1475-1486.

LABONNE C, WHITMAN M (1994). Mesoderm induction by activin requires FGFmediated intracellular signals. Development 472: 463-472.

LAVINE KJ, YU K, WHITE AC, ZHANG X, SMITH C, PARTANEN J, ORNITZ DM (2005). Endocardial and epicardial derived FGF signals regulate myocardial proliferation and differentiation in vivo. Dev Cell 8: 85-95.

LEA R, PAPALOPULU N, AMAYA E, DOREY K (2009). Temporal and spatial expression of FGF ligands and receptors during Xenopus development. Dev Dyn 238 : 1467-1479.

LECARME, O. AND DELVARE K (2013). The book of GIMP: A complete guide to nearly everything. No Starch Press (San Francisco, CA, USA)

LU Shun Yan, SHEIKH F, SHEPPARD PC, FRESNOZA A, DUCKWORTH ML, DETILLIEUX KA, CATTINI PA (2008). FGF-16 is required for embryonic heart development. Biochem Biophys Res Commun 373: 270-274.

LU S.Y., SONTAG DP, DETILLIEUX KA, CATTINI PA (2008). FGF-16 is released from neonatal cardiac myocytes and alters growth-related signaling: a possible role in postnatal development. Am J Physiol Physiol 294: 1242-1249.

MAJELLO B, LUCA P De, LANIA L (1997). Sp3 Is a bifunctional rranscription regulator with modular independent activation and repression domains. J Biol Chem 272: 4021-4026

MIGNATTI P, MORIMOTO T, RIFKIN DB (1992). Basic fibroblast growth factor, a protein devoid of secretory signal sequence, is released by cells via a pathway independent of the endoplasmic reticulum-Golgi complex. J Cell Physiol151:81-93.

MIYAKAWA K, HATSUZAWA K, KUROKAWA T, ASADA M, KUROIWA T, IMAMURA $T$ (1999). A hydrophobic region locating at the center of fibroblast growth factor- 9 is crucial for its secretion. J Biol Chem 274: 29352-29357.

MIYAKAWA K, IMAMURA T (2003). Secretion of FGF-16 requires an uncleaved bipartite signal sequence. J Biol Chem 278: 35718-35724.

MIYAKE a, KONISHI M, MARTIN FH, HERNDAY $\mathrm{N}$ a, OZAKI K, YAMAMOTO $S$, MIKAMI T, ARAKAWA T, ITOH N (1998). Structure and expression of a novel member, FGF-16, on the fibroblast growth factor family. Biochem Biophys Res Commun 243: 148-152.

MIYAKE A, CHITOSE T, KAMEI E, MURAKAMI A, NAKAYAMA Y, KONISHI M, ITOH $\mathrm{N}$ (2014). FGF16 is required for specification of GABAergic neurons and oligodendrocytes in the zebrafish forebrain. PLoS One 9(10):e110836. doi: 10.1371/ journal.pone.0110836. eCollection 2014.

MOHAMMADI M, EIISEENKOVAA V., SCHLESSINGER J, HUBBARD SR, FROUM S, GREEN D, HAMBY JM, SCHROEDER MC, PANEK RL, LU GH (1998). Crystal structure of an angiogenesis inhibitor bound to the FGF receptor tyrosine kinase domain. EMBO J 17: 5896-5904.

NICHOLAS K. (1997). GeneDoc: analysis and visualization of genetic variation. Embnew news 4: 14

NICKEL W (2010). Pathways of Unconventional Protein Secretion. Curr Opin Biotechnol 21: 621-626.

NIEUWKOOP, P.D. AND FABER J (1967). Normal table of Xenopus laevis (Daudin): A systematical and chronological survey of the development from the fertilized egg till the end of metamorphosis. North Holl Publ Company, Amsterdam.

NOMURA R, KAMEI E, HOTTA Y, KONISHI M, MIYAKE A, ITOH N (2006). FGF16 is essential for pectoral fin bud formation in zebrafish. Biochem Biophys Res Commun 347: 340-346.

NORTHROP JL, KIMELMAN D (1994). Dorsal-ventral differences in Xcad-3 expression in response to FGF-mediated induction in Xenopus. Dev Biol 161: 490-503.

OLAYA-SÁNCHEZ D, SÁNCHEZ-GUARDADO LÓ, OHTA S, CHAPMAN SC, SCHOENWOLF GC, PUELLES L, HIDALGO-SÁNCHEZ M (2017). FGF3 and FGF16 expression patterns define spatial and temporal domains in the developing chick inner ear. Brain Struct Funct 222: 131-149.

ONG SH, GUY GR, HADARI YR, LAKS S, GOTOH N, SCHLESSINGER J, LAX I (2000). FRS2 proteins recruit intracellular signaling pathways by binding to diverse targets on fibroblast growth factor and nerve growth factor receptors. Mol Cell Biol 20: 979-989.

ORNITZ DM, ITOH N (2015). The fibroblast growth factor signaling pathway. Wiley Interdiscip Rev Dev Biol 4: 215-266.

ORNITZ DM, XU J, COLVIN JS, MCEWEN DG, MACARTHUR CA, COULIER F GAO G, GOLDFARB M (1996). Receptor specificity of the fibroblast growth factor family. J Biol Chem 271: 15292-15297. 
OSSIPOVA O, STICK R, PIELER T (2002). XSPR-1 and XSPR-2, novel Sp1 related zinc finger containing genes, are dynamically expressed during Xenopus embryogenesis. Mech Dev 115: 117-122.

OWENS NDL, BLITZ IL, LANE MA, PATRUSHEV I, OVERTON JD, GILCHRIST MJ, CHO KWY, KHOKHA MK (2016). Measuring absolute RNA copy numbers at high temporal resolution reveals transcriptome kinetics in development. Cell Rep 14: 632-647.

PARK D, SEO J, HONG M, BANG W, HAN J (2013). Role of Sp5 as an essential early regulator of neural crest specification in Xenopus. Dev Dyn 242: 1382-1394.

PEI J, GRISHIN N V (2015). C2H2 zinc fi nger proteins of the SP / KLF, Wilms tumor, EGR, Huckebein, and Klumpfuss families in metazoans and beyond. Gene 573: 91-99.

PHAN D, CHENG C, GALFIONE M, VAKAR-LOPEZ F, TUNSTEAD J, THOMPSON NE, BURGESS RR, NAJJAR SM, LIN S (2004). Identification of Sp2 as a transcriptional repressor of carcinoembryonic antigen- related cell adhesion molecule 1 in tumorigenesis. Cancer Res 64: 3072-3078.

POWNALL ME, TUCKER AS, SLACK JMW, ISAACS H V (1996). eFGF, Xcad3 and Hox genes form a molecular pathway that establishes the anteroposterior axis in Xenopus. Development 3892: 3881-3892.

PRESNELL JS, SCHNITZLER CE, BROWNE WE (2015). KLF/SP transcription factor family evolution: expansion, diversification, and innovation in eukaryotes. Genome Biol Evol 7: 2289-2309.

PRIYAM A, WOODCROFT BJ, RAI V, MUNAGALA A, MOGHUL I, TER F (2015). Sequenceserver : a modern graphical user interface for custom BLAST databases. BioRxiv: 1-18.

RANDI AM, SPERONE A, DRYDEN NH, BIRDSEY GM (2009). Regulation of angiogenesis by ETS transcription factors. Biochem Soc Trans 37: 1248-1253.

REVEST JM, DEMOERLOOZE L, DICKSON C (2000). Fibroblast growth factor 9 secretion is mediated by a non-cleaved amino-terminal signal sequence. $J$ Biol Chem 275: 8083-8090.

SANTOS-OCAMPO S, COLVIN JS, CHELLAIAH A, ORNITZ DM (1996). Expression and biological activity of mouse fibroblast growth factor-9. J Biol Chem 271: 1726-1731.

SESSION AM, UNO Y, KWON T, CHAPMAN JA, TOYODAA, TAKAHASHI S, FUKUI A, HIKOSAKA A, SUZUKI A, KONDO M, et al., (2016). Genome evolution in the allotetraploid frog Xenopus laevis. Nature 538: 336-343.

SLACK JM, DARLINGTONBG, HEATH JK, GODSAVESF (1987). Mesoderm induction in early Xenopusembryos by heparin-binding growth factors. Nature 326: 197-200.

SQUARE T, JANDZIK D, CATTELL M, COEA, DOHERTY J, MEULEMANS D (2015). A gene expression map of the larval Xenopus laevis head reveals developmental changes underlying the evolution of new skeletal elements. Dev Bio/397:293-304.

TABE L, KRIEG P, STRACHAN R, JACKSON D, WALLIS E, COLMANA (1984). Segregation of mutant ovalbumins and ovalbumin-globin fusion proteins in Xenopus oocytes. Identification of an ovalbumin signal sequence. J Mol Biol 180: 645-666.
TALLAFUSS A, WILM TP, CROZATIER M, PFEFFER P, WASSEF M, BALLY-CUIF L (2001). The zebrafish buttonhead-like factor Bts1 is an early regulator of pax2. 1 expression during mid-hindbrain development. Development 4034: 4021-4034.

TOKUOKA M, IMAI KS, SATOU Y, SATOH N (2004). Three distinct lineages of mesenchymal cells in Ciona intestinalis embryos demonstrated by specific gene expression. Dev Biol 274: 211-224.

TUCKER AS, SLACK JMW (1995). The Xenopus laevis tail-forming region. Dev Biol 121: 249-262.

TURNBULL, J., POWELL, A. AND GUIMOND S (2001). Heparan sulfate: decoding a dynamic multifunctional cell regulator. Trends Cell Biol 11: 75-82.

UMBHAUER M, MARSHALL CJ, MASON CS, OLD RW (1995). Mesoderm induction in Xenopus caused by activation of MAP kinase. Nature 376: 58-62.

VON HEIJNE G, LILJESTRÖM P, MIKUS P, ANDERSSON H, NY T (1991). The efficiency of the uncleaved secretion signal in the plasminogen activator inhibitor type 2 protein can be enhanced by point mutations that increase its hydrophobicity. J Biol Chem 266: 15240-15243.

WANG J, SONTAG D, CATTINI PA (2015). Heart-specific expression of FGF-16 and a potential role in postnatal cardioprotection. Cytokine Growth Factor Rev26:59-66.

WEIDINGER G, THORPE CJ, WUENNENBERG-STAPLETON K, NGAI J, MOON RT (2005). The Sp1-related transcription factors sp5 and sp5-like act downstream of Wnt/B-Catenin Signaling in mesoderm and neuroectoderm patterning 269 Life Sciences Addition 3200. Curr Biol 15: 489-500.

WHITMAN M, MELTON DA (1992). Involvement of p21 ras in Xenopus mesoderm induction. Nature 357: 252-254.

YEH BK, IGARASHI M, ELISEENKOVA A V., PLOTNIKOV AN, SHER I, RON D, AARONSON SA, MOHAMMADI M (2003). Structural basis by which alternative splicing confers specificity in fibroblast growth factor receptors. Proc Natl Acad Sci USA 100: 2266-2271.

ZEHEC, ENGLINGA, WEGEHINGELS, SCHAFERT, NICKELW (2006). Cell-surface heparan sulfate proteoglycans are essential components of the unconventional export machinery of FGF-2. Proc Natl Acad Sci USA 103: 15479-15484.

ZHANG X, IBRAHIMI OA, OLSEN SK, UMEMORI H, MOHAMMADI M, ORNITZ DM (2006). Receptor specificity of the fibroblast growth factor family: The complete mammalian FGF family. J Biol Chem 281: 15694-15700.

ZHAO C, MENG A (2005). Sp1-like transcription factors are regulators of embryonic development in vertebrates. Dev Growth Differ 47: 201-211.

ZHAO J, CAO Y, ZHAO C, POSTLETHWAIT J, MENG A (2003). An SP1-like transcription factor Spr2 acts downstream of FGF signaling to mediate mesoderm induction. EMBO J 22: 6078-6088. 


\section{Further Related Reading, published previously in the Int. J. Dev. Biol.}

FoxD1 protein interacts with Wnt and BMP signaling to differentially pattern mesoderm and neural tissue

Hanna Polevoy, Anastasia Malyarova, Yuri Fonar, Sara Elias and Dale Frank

Int. J. Dev. Biol. (2017) 61: 293-302

Competition for ligands between FGFR1 and FGFR4 regulates Xenopus neural development

Masahiro Yamagishi and Harumasa Okamoto

Int. J. Dev. Biol. (2010) 54: 93-104

A dynamic requirement for community interactions during Xenopus myogenesis. Henrietta J Standley, Aaron M Zorn and John B Gurdon Int. J. Dev. Biol. (2002) 46: 279-283

\section{Expression and functions of FGF-3 in Xenopus development} A Lombardo, $\mathrm{H}$ V Isaacs and J M Slack Int. J. Dev. Biol. (1998) 42: 1101-117 http://www.intjdevbiol.com/web/paper/9879707

eFGF is expressed in the dorsal midline of Xenopus laevis. $\mathrm{H}$ V Isaacs, M E Pownall and J M Slack Int. J. Dev. Biol. (1995) 39: 575-579
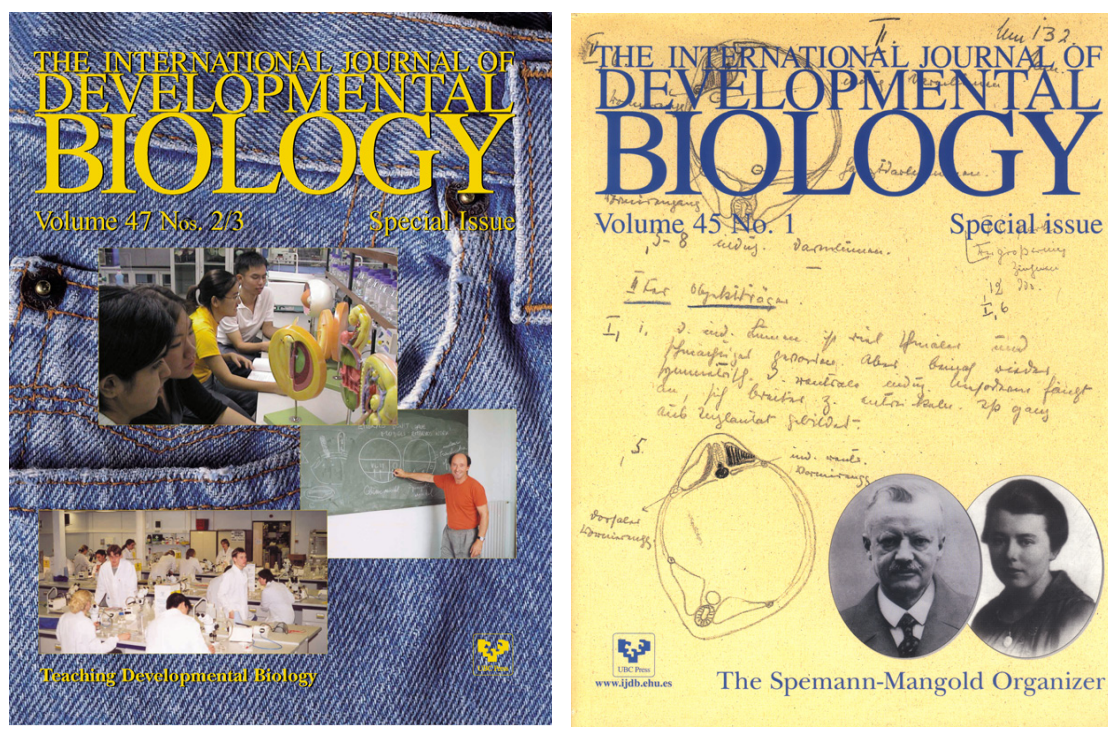

Volume 45 No. 1

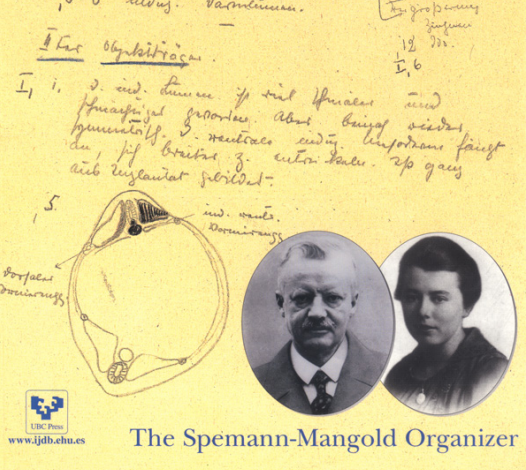

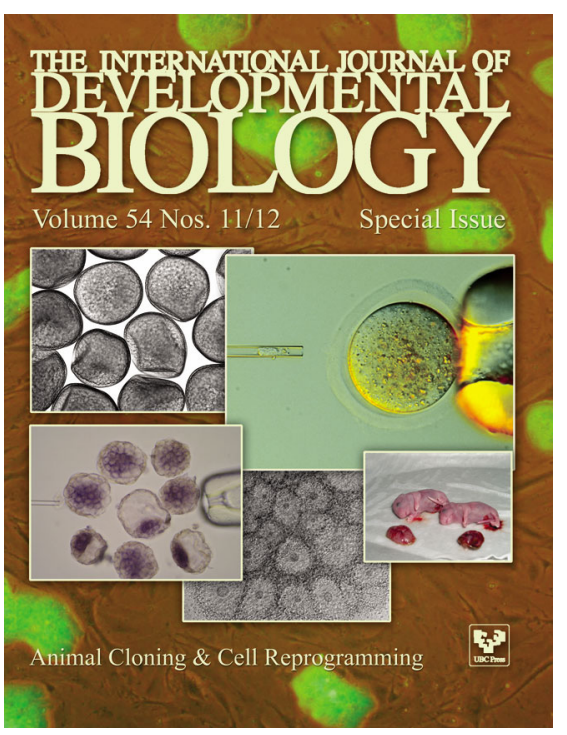

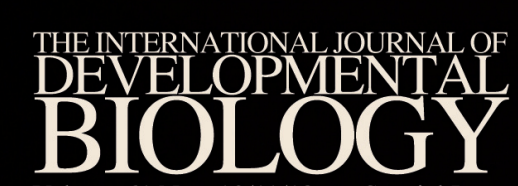

Volume 61 Nos. 10/11/12

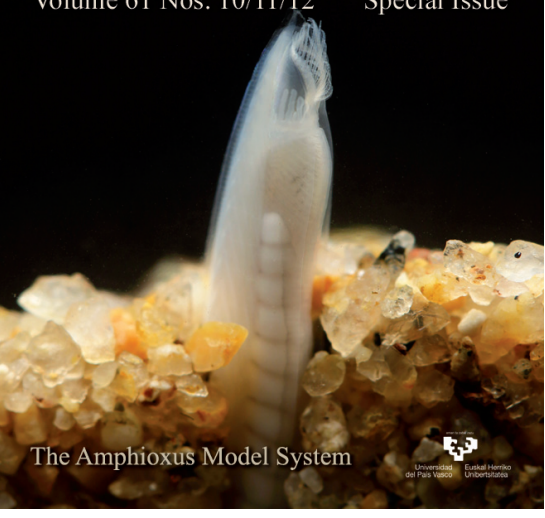

